\title{
THE TREATMENT WITH MYCOPHENOLATE MOFETIL OF CORTICORESISTENT NEPHROTIC SYNDROME BY IDIOPATHIC FOCAL SEGMENTAL GLOMERULOSCLEROSIS: ANALYSIS OF TWENTY CASES
}

\author{
Merita Rroji $^{1}$, Nereida Spahia ${ }^{1}$, Myftar Barbullushi ${ }^{1}$ and Mauro Sasdelli ${ }^{2}$
}

${ }^{1}$ Service of Nephrology, University Hospital Centre "Mother Teresa", Tirana, Albania
${ }^{2}$ Ex Chief of Nephrology Department of St. Donato Hospital, Arezzo, Italy

Corresponding author: Merita Rroji PhD, University Hospital Center " Mother Tereza”, Department of Nephrology, Tirana, Albania, e-mail: meritarroji@yahoo.com

The Idiopathic Focal Segmental Glomerulosclerosis (FSGS) is one of the most frequent glomerular nephropathies affecting both children and adults. The morphological/histological pattern recognized on kidney biopsy is characterized by sclerotic (fibrotic) lesions in glomeruli that are focal (less than $50 \%$ of all glomeruli affected on light microscopy) and segmental (less than $50 \%$ of the glomerular tuft affected). This pathological pattern has been further classified by the Columbia group according to specific pathological light microscopic findings (tip lesion, cellular, collapsing, perihilar and not otherwise specified) [1]. Podocyte injury is the earliest morphological feature of FSGS, which has led to the current paradigm that classic FSGS is primarily a podocyte disorder, at least initially [2]. The prognosis of FSGS is predicted by the severity and persistence of proteinuria, with $60 \%$ of patients with persistent nephrotic-range proteinuria progressing to end-stage renal disease within 5-10 years. Achievement of a remission, whether complete or partial, is associated with a good outcome [3].

At present, corticosteroids are the standard first-line approach in patients with idiopathic FSGS. Cytotoxic agents and cyclosporin A constitute a good therapeutic option for steroid-dependent patients or frequent relapses. During the last years, the use of Mycophenolate Mofetil (MMF) has been proposed in the Nephrotic Syndrome by FSGS together with steroids (4 observational studies [4. 5] and one randomized trial [6] suggests that MMF given with or without glucocorticoids may be beneficial in patients with FSGS with varying results, but with the advantage of a lower toxicity compared with other immunosuppressants [4-7].

We analysed the data of our twenty patients with a histological diagnosis of Focal and Segmental Glomerulosclerosis having a resistant or relapsing nephrotic syndrome, who have been previously treated with steroids and immunosuppressive [six patients with steroids alone (two with boluses of $500 \mathrm{mg} \times 3$ days and then steroids per os, four with steroids per os), eight patients with steroids + cyclophosphamide, five patients with steroids + cyclosporine and one patient steroids + azathioprine] and who had not responded to treatment. Afterwards, therapy with MMF associated with Methylprednisolone $(0.5 \mathrm{mg} / \mathrm{kg}$ every other day $)$ was started and continued for $10.2 \pm 2.8$ months). Patients were put on a regime with Mycophenolate (Cell Cept) $1 \mathrm{~g} /$ day for a month and then, if well tolerated, the dose was increased to $2 \mathrm{~g} /$ day with a first step at 6 months. If the Nephrotic Syndrome was in complete remission MMF was suspended, otherwise it was continued for up to 12 months with follow-up of the patients. In two cases with a creatinine level greater than $2 \mathrm{mg} / \mathrm{dl}$ and a glomerular filtrate less than $50 \mathrm{ml} / \mathrm{min}$ it was used a dose of Mycophenolate of $1 \mathrm{~g} /$ day. In addition, in all patients therapy with Ramipril, Calcium and vitamin D3 was used. At the end of MMF therapy, we observed a remission in eleven patients $(55 \%)$, two of which with complete remission $10 \%$, an incomplete remission in three patients $(15 \%)$, a partial remission in six patients $30 \%$, no response in eight patients (40\%) and a worsening of kidney function in one patient (5\%). This can be considered 
a good outcome, considering that these patients did not respond to previous therapies. In eight patients, the Nephrotic Syndrome remained unchanged, two of which suspended early therapy for side effects (gastric intolerance), while in one case the therapy was suspended due to the worsening of renal function. After treatment, the mean urinary protein excretion significantly decreased compared with baseline $[7.68 \pm 3.54$ to $3.20 \pm 2.92 \mathrm{~g} /$ day, $(\mathrm{p}<$ $0.001)$ ], while plasma creatinine and the glomerular filtrate did not show significant variations. In our view this is an important result, as remission either complete or partial, is the critical factor for predicting renal survival in nephrotic syndrome due to primary FSGS with 5-year renal survival of about $90 \%$ [5]. In addition, the results remain stable also at the end of follow up (19.2 \pm 18.9 months). The results of this study, despite the relatively low number of patients, can have an additional clinical impact, considering the high remission rate and the good side effect profile observed with MMF regime in the treatment of Nephrotic Syndrome due to FSGS resistant to other drugs. The MMF is an immunosuppressant which acts by inhibiting the purine synthesis by a selective, non-competitive and reversible inhibition of inosine monophosphate dehydrogenase, which is the rate-limiting enzyme in the de novo biosynthesis of guanosine nucleotides. It strongly inhibits both $\mathrm{T}$ - and $\mathrm{B}$ lymphocyte proliferation. Moreover, MMF is also capable of inhibiting the proliferation of non-immune cells as smooth muscle cells, renal tubular cells and mesangial cells and prevents the appearance of Heymann Nephritis [8,9]. In the animal studies, MMF reduces the expression of nitric oxide synthase at the cortical level by decreasing glomerulosclerosis [10]. MMF showed beneficial effects in the treatment of calcineurin inhibitor toxicity through reduction of immune - and non-immune-mediated renal damage [11]. Nevertheless, it is well tolerated and has proven to be a relatively safe drug causing only minor bone marrow suppression [4-7]. In addition, there is a growing body of evidence pointing to therapeutic applications of MMF in the prevention of fibrosis [12]. These observations prompted several investigators to study the effects of MMF in human renal diseases. While it was noted that the MMF significantly reduced proteinuria in minimal-change disease, especially in the steroid-resistant nephrotic syndrome of children [13] the results for Focal segmental glomerulosclerosis (FSGS) [14], were very variable and even more controversial. Our results give an additional confirmation for the benefits of MMF regime in FSGS being an therapeutic alternative with favourable effects and most importantly with reduced side effects, in comparison to Calcineurin inhibitors such as Cyclosporine, which however has a high renal toxicity.

\section{Conflict of Interest}

The authors declare that they have no conflict of interest.

The authors alone are responsible for the content and writing of the paper.

\section{Ethical approval}

"The study presented was in accordance with the ethical standards of the institutional and/ or national research committee and with the 1964 Helsinki declaration and its later amendments or comparable ethical standards."

\section{REFERENCES}

1. D'Agati VD, et al: Pathologic classification of focal segmental glomerulosclerosis: a working proposal. Am J Kidney Dis 2013; 43: 368-382.

2. Parsa A, et al: APOL1 risk variants, race, and progression of chronic kidney disease. N Engl J Med 2013; 369: 2183-2196.

3. Deegens JKJ: Immunosuppressive treatment of focal segmental glomerulosclerosis: lessons from a randomized controlled trial. Kidney Int 2011; 80: 798-01.

4. Alfonso Segarra Medrano et al: Treatment of idiopathic focal segmental glomerulosclerosis: options in the event of resistance to corticosteroids and calcineurin inhibitors. Nefrologia 2013; 33 (4): 443-622.

5. Cattran, D.C, et al: Mycophenolate mofetil in the treatment of focal segmental glomerulosclerosis. Clin Nephrol 2004; 62: 405-411.

6. Gipson DS, Trachtman H, Kaskel FJ, et al. Clinical trial of focal segmental glomerulosclerosis in children and young adults. Kidney Int 2011; 80: 868.

7. Fernandez-Juarez G, et al: Therapeutic variability in adult minimal change disease and focal segmental glomerulosclerosis.Clin Kidney J 2016; 9: 381-6.

8. Morath $\mathrm{C}$, Zeier M: Review of the antiproliferative properties of mycophenolate mofetil in non-immune cells. Int $\mathrm{J}$ Clin Pharmacol Ther 2003; 41: 465-9. 
9. Penny MJ, et al: Mycophenolate mofetil prevents the induction of active Heymann nephritis: association with Th2 cytokine inhibition. J Am Soc Nephrol 1998; 12: 2272-82.

10. Wu Y, et al: Shen Nephrin and podocin loss is prevented by mycophenolate mofetil in early experimental diabetic nephropathy. J.Citokine 2008; 44: 85-91.

11. Yang CW, et al: Cyclosporine withdrawal and mycophenolate mofetil treatment effects on the progression of chronic cyclosporine nephrotoxicity. Kidney Int 2002; 62: 20-30.

12. Morath $\mathrm{C}$, et al. Antifibrotic actions of mycophenolic acid. Clin Transplant 2005; 20 S: 25-9.

13. Li Z, Duan C, et al: Mycophenolate mofetil therapy for children with steroid-resistant nephrotic syndrome. Pediatr Nephrol 2010; 25: 883-888.

14. Beer A, et al: Treatment Strategies of Adult Primary Focal Segmental Glomerulosclerosis: A Systematic Review Focusing on the Last Two Decades. Biomed Res Int 216; 4192578. 